\title{
An Investigation on Tribological Properties and Lubrication Mechanism of Graphite Nanoparticles as Vegetable Based Oil Additive
}

\author{
Yu Su, Le Gong, and Dandan Chen \\ College of Mechanical Engineering, Jiangsu University of Science and Technology, Zhenjiang 212003, China \\ Correspondence should be addressed to Yu Su; yusu2000@nuaa.edu.cn
}

Received 22 March 2015; Accepted 20 April 2015

Academic Editor: Stefano Bellucci

Copyright @ $2015 \mathrm{Yu}$ Su et al. This is an open access article distributed under the Creative Commons Attribution License, which permits unrestricted use, distribution, and reproduction in any medium, provided the original work is properly cited.

This paper used graphite nanoparticles with the diameter of 35 and $80 \mathrm{~nm}$ and LB2000 vegetable based oil to prepare graphite oil-based nanofluids with different volume fractions by two-step method. The tribological properties of graphite nanoparticles as LB2000 vegetable based oil additive were investigated with a pin-on-disk friction and wear tester. Field emission scanning electron microscope (FE-SEM) and energy dispersive spectroscopy (EDS) were used to examine the morphology and the content of some typical elements of wear scar, respectively. Further, the lubrication mechanism of graphite nanoparticles was explored. It was found that graphite nanoparticles as vegetable based oil additive could remarkably improve friction-reducing and antiwear properties of pure oil. With the increase of volume fraction of graphite nanoparticles, the friction coefficient and the wear volume of disk decreased. At the same volume fraction, the smaller particles, the lower friction coefficient and wear volume. The main reason for the improvement in friction-reducing and antiwear properties of vegetable based oil using graphite nanoparticles was that graphite nanoparticles could form a physical deposition film on the friction surfaces.

\section{Introduction}

In manufacturing process, friction and wear result in the increase of energy consumption and the reduction in the life of mechanical parts. Therefore, how to reduce the friction and wear is an important issue, which needs to be studied urgently. The oil is a kind of traditional medium to reduce the friction and wear. However, with the development of mechanical manufacturing technology, high temperature and pressure during the friction process make the oil work not so well, which requires enhancing the lubrication characteristics of oil.

Nanofluids are fluids obtained by suspending nanoparticles with average sizes below $100 \mathrm{~nm}$ in base fluids [1]. Many researchers have reported that the addition of nanoparticles can improve the tribological properties of pure oil. Nanoparticles that have been employed as pure oil additive are graphite [2-4], molybdenum disulfide [5-7], and carbon nanotubes [8-10]. Huang et al. [11] synthesized graphite nanosheets with average diameter of $500 \mathrm{~nm}$ by stirring ball milling and evaluated the tribological properties of graphite nanosheets as paraffin oil additive. It was found that the antiwear ability and load carrying capacity of paraffin oil could be improved by the addition of graphite nanosheets. Lee et al. [12] carried out the friction and wear tests using super gear oil (EP220) containing graphite nanoparticles and reported that the addition of graphite nanoparticles to the pure oil led to a lower friction coefficient and less wear rate. Prasad et al. [13] discussed sliding wear characteristics of a gray cast iron over a range of applied loads using mineral oil containing graphite nanoparticles. The wear rate of cast iron increased with load in general, while the addition of $5 \mathrm{wt} . \%$ graphite to the pure oil brought about a decrease in the wear rate. When the concentration was higher than $10 \mathrm{wt} . \%$, the wear rate significantly decreased at high loads. Hwang et al. [14] studied the tribological behaviors of graphite nanoparticles as mineral oil additive using a disc-on-disc tribotester and found that the improvement in friction-reducing and antiwear properties of pure oil was attributed to the presence of spherical nanoparticles, which prevented direct contact between frictional surfaces. An et al. [15] produced nanolamellar tungsten and molybdenum 
TABle 1: Properties of graphite nanoparticles.

\begin{tabular}{lc}
\hline Properties & Graphite \\
\hline Average particle size $/(\mathrm{nm})$ & 35,80 \\
Specific gravity $\left(@ 20^{\circ} \mathrm{C}\right) /\left(\mathrm{g} / \mathrm{cm}^{3}\right)$ & 1.80 \\
Purity/(\%) & 99.9 \\
\hline
\end{tabular}

TABLE 2: Properties of LB2000 vegetable based oil.

\begin{tabular}{lc}
\hline Properties & LB2000 vegetable based oil \\
\hline Specific gravity $\left(@ 20^{\circ} \mathrm{C}\right) /\left(\mathrm{g} / \mathrm{cm}^{3}\right)$ & 0.92 \\
Dynamic viscosity $\left(@ 40^{\circ} \mathrm{C}\right) /(\mathrm{mpa} \cdot \mathrm{s})$ & 34.04 \\
Flash point $/\left({ }^{\circ} \mathrm{C}\right)$ & 320 \\
Pour point $/\left({ }^{\circ} \mathrm{C}\right)$ & -20 \\
Sulfur & None \\
chlorine & None \\
Mineral oil $/(\%)$ & 0 \\
Water solubility & Insoluble \\
\hline
\end{tabular}

disulfides and conducted the tribological tests using oil-based lubricants added with the prepared and commercial powder. The results indicated that the oil-based lubricants with nanolamellar disulfide additives displayed higher antifriction and antiwear properties compared to commercial powder. Cursaru et al. [16] used a pin-on-disk tribometer to explore the friction-reducing and antiwear properties of SWNTs as mineral oil additive. The results suggested that the addition of $0.5 \mathrm{wt} . \%$ SWNTs to base oil could reduce the friction coefficient from 0.105 to 0.08 ; meanwhile the wear rate was minimum. Higher additive concentrations did not result in the reduction of friction coefficient and wear rate.

The literature review shows that less work has been done on the addition of graphite nanoparticles to improve the lubrication characteristics of vegetable based oil. Therefore, the object of this paper is to investigate the tribological properties of graphite nanoparticles as vegetable based oil additive and reveal the lubrication mechanism of graphite nanoparticles.

\section{Experimental Details}

2.1. Preparation of Graphite Oil-Based Nanofluids. Since twostep method is simple, it was used to prepare graphite oilbased nanofluids in this paper. The base fluid used in this research was LB2000 vegetable based lubricant, which is produced by ITW Rocol North American Co., Ltd. Graphite nanoparticles with the diameter of 35 and $80 \mathrm{~nm}$, purchased from Beijing DK Nano Technology and Xuzhou Jiechuang New Material Technology Co., Ltd., respectively, were used throughout these experiments. The properties of graphite nanoparticles and LB2000 vegetable based oil are listed in Tables 1 and 2, respectively.

The graphite-LB2000 nanofluids with different volume fractions ranging from $0.05 \%$ to $0.25 \%$ were prepared at ambient temperature by dispersing a certain amount of graphite nanoparticles in LB2000 vegetable based oil using KQ-100DE ultrasonic cleaner with a $100 \mathrm{~W}$ output power and

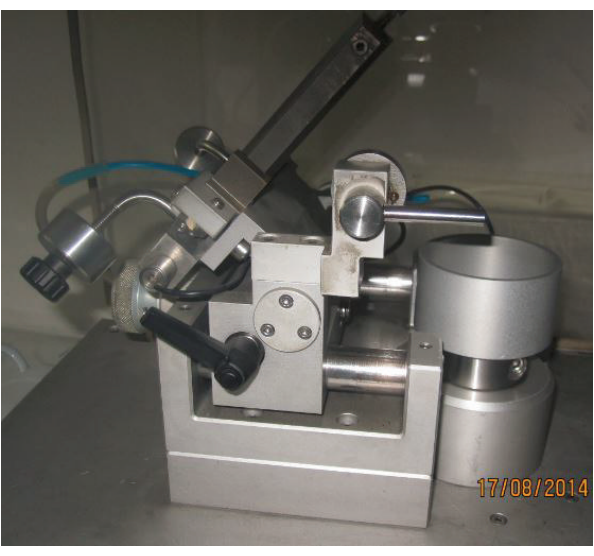

FIGURE 1: Pin-on-disk tribotester.

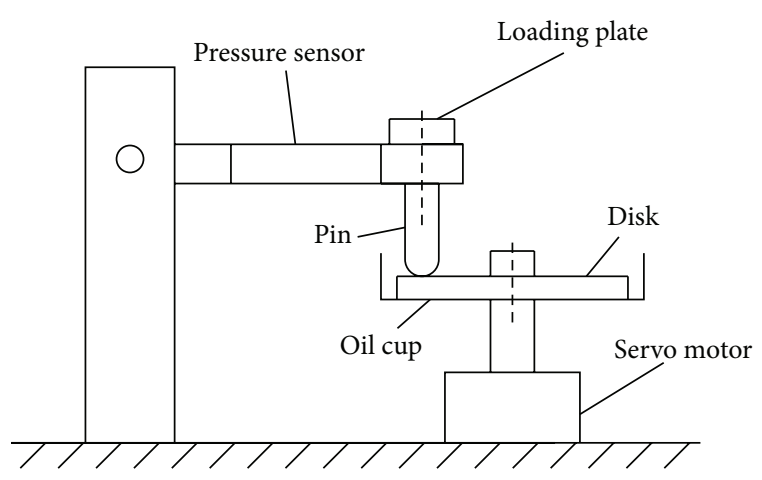

FIGURE 2: Schematics diagram of pin-on-disk tribotester.

40 KHZ frequency. To obtain a good dispersity and stability of graphite nanoparticles in LB2000 vegetable based oil, the ultrasonication time used was $1.0 \mathrm{~h}$ for most of nanofluids prepared. However, the ultrasonication time was $1.5 \mathrm{~h}$ for graphite-LB2000 nanofluids prepared with $80 \mathrm{~nm}$ graphite nanoparticles with the volume fraction of $0.25 \%$.

2.2. Friction and Wear Experiment. A pin-on-disk friction and wear tester (Figure 1), which is produced by Swiss CSM Co., Ltd., was used to study the tribological properties of graphite nanoparticles as vegetable based oil additive. Figure 2 presents the basic configuration of pin-on-disk tribotester.

The pin and disk were fixed on the stent and test bench, respectively. Loading weight was put on the top of pin; thus a positive pressure was produced. The servo motor drove the rotating shaft and test bench according to the specific rotation speed. A relative sliding was produced between pin and disk, constituting a pair of sliding friction pairs. The pin $(\Phi 6 \times$ $20 \mathrm{~mm})$ and disk $(\Phi 30 \times 7.8 \mathrm{~mm})$ were made of cemented carbide and Ti-6Al-4V titanium alloy, respectively. Before friction and wear experiments, the surface of disk was ground with a 200 and 800 mesh sandpaper, respectively. Thus the surface roughness of disk obtained was $R a=0.4 \mu \mathrm{m}$. The basic composition and mechanical properties of friction pairs are shown in Table 3. 
TABLE 3: The basic composition and mechanical properties of friction pairs.

\begin{tabular}{lcc}
\hline Properties & Pin & Disk \\
\hline Material & YG8 cemented carbide & Ti-6Al-4V titanium alloy \\
Composition & $92 \% \mathrm{WC}+8 \% \mathrm{Co}$ & $90 \% \mathrm{Ti}+6 \% \mathrm{Al}+4 \% \mathrm{~V}$ \\
Density $\left(920^{\circ} \mathrm{C}\right) /\left(\mathrm{g} / \mathrm{cm}^{3}\right)$ & $14.5 \sim 14.9$ & 4.5 \\
Hardness & $89 \sim 90 \mathrm{HRA}$ & $290 \sim 356 \mathrm{HV}$ \\
Elastic modulus $/(\mathrm{GPa})$ & $600 \sim 610$ & 109 \\
\hline
\end{tabular}

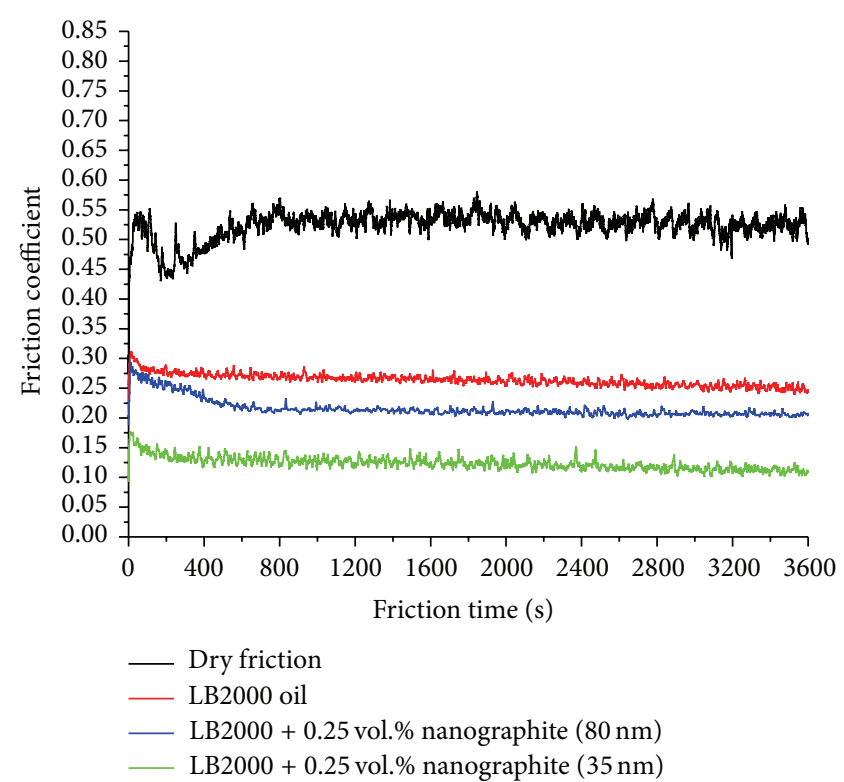

(a) $F=2 \mathrm{~N}$
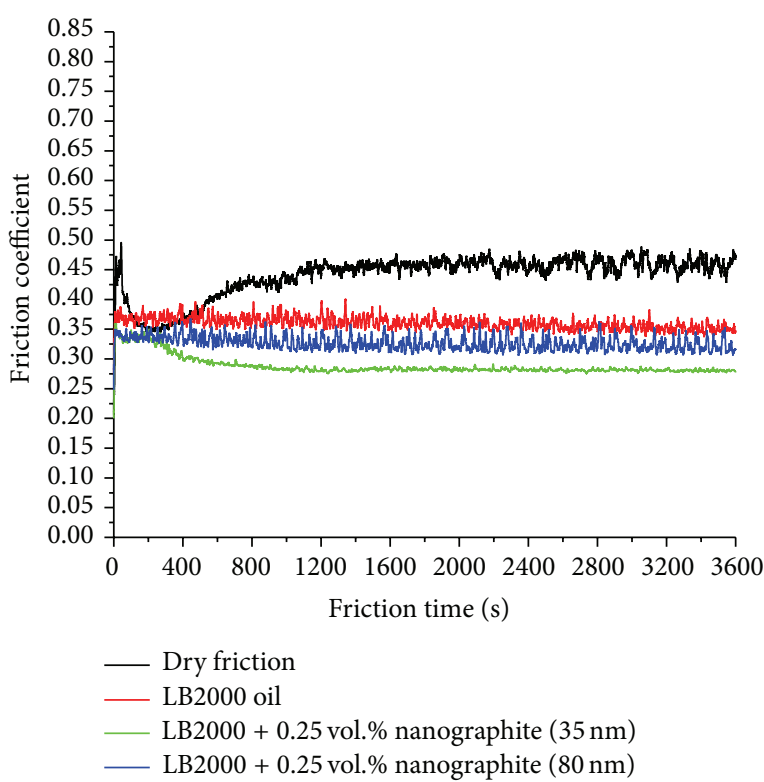

(b) $F=10 \mathrm{~N}$

FIGURE 3: Variation of friction coefficient with friction time for various lubrication conditions.

The variation of friction coefficient with friction time was recorded automatically. The wear volume of disk was measured by the Micro XAM-3D surface profiler. After the friction and wear experiments, the specimens were cleaned using an ultrasonic bath in petroleum ether for $10 \mathrm{~min}$. The topographies of wear scars of disks were observed using a JSM-7001F and S-4800 field emission scanning electron microscope (FE-SEM). The content of some typical elements on the surfaces of wear scars was examined on energy dispersive spectroscopy (EDS). The detailed experimental conditions are shown in Table 4.

\section{Results and Discussion}

3.1. Influence of Graphite Nanoparticles on Friction-Reducing Property of Vegetable Based Oil. Figure 3 shows the variation of friction coefficient with friction time for various lubrication conditions. It can be seen from Figure 3 that, under dry friction condition, with the increase of friction time, the friction coefficient decreased firstly, then increased, and eventually reached a stable state. In terms of dry friction, the friction coefficient at a high normal force was lower than that at a low normal force. This may be due to the formation of oxide film caused by high temperature and pressure during friction process. Under the condition of vegetable based
TABLE 4: Conditions of friction and wear tests.

\begin{tabular}{ll}
\hline Experimental parameters & Values \\
\hline Relative humidity $H /(\%)$ & 47 \\
Temperature $T /\left({ }^{\circ} \mathrm{C}\right)$ & 24 \\
Normal force $F /(\mathrm{N})$ & 2,10 \\
Friction radius $R /(\mathrm{mm})$ & 6 \\
Rotating speed $n /(\mathrm{r} / \mathrm{min})$ & 100 \\
Friction time $t /(\mathrm{min})$ & 60 \\
& Dry friction \\
& Lubricated with LB2000 \\
& vegetable based oil \\
& Lubricated with LB2000 \\
& vegetable based oil with graphite \\
& nanoparticles with the volume \\
Lubrication conditions & fraction ranging from $0.05 \%$ to \\
& $0.25 \%$ \\
\hline
\end{tabular}

oil and vegetable based oil with graphite nanoparticles, the friction coefficient gradually decreased and then got to a steady value. As shown in Figure 3, the friction coefficient under the condition of vegetable based oil and vegetable based oil with graphite nanoparticles was lower than that under dry friction condition almost on the whole friction 


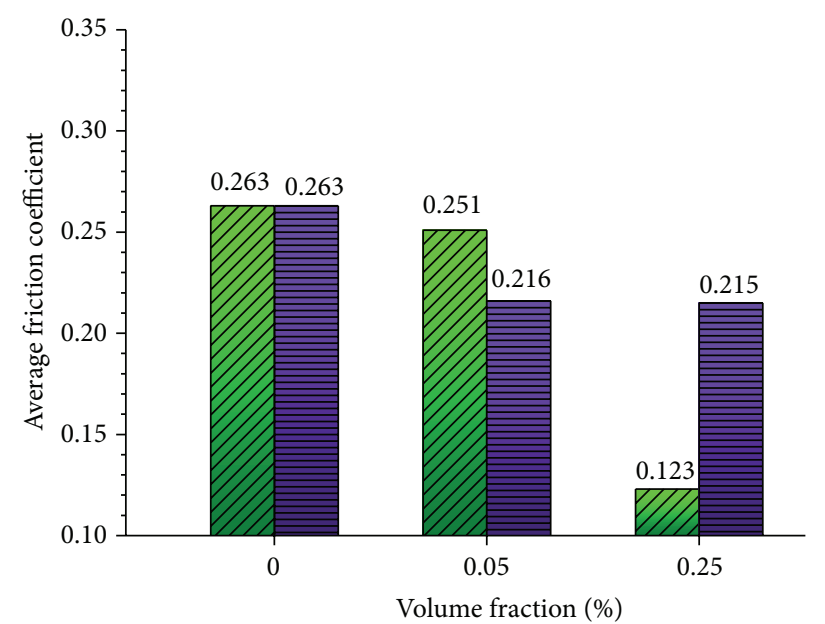

LB2000 + nanographite $(35 \mathrm{~nm})$

LB2000 + nanographite $(80 \mathrm{~nm})$

(a) $F=2 \mathrm{~N}$

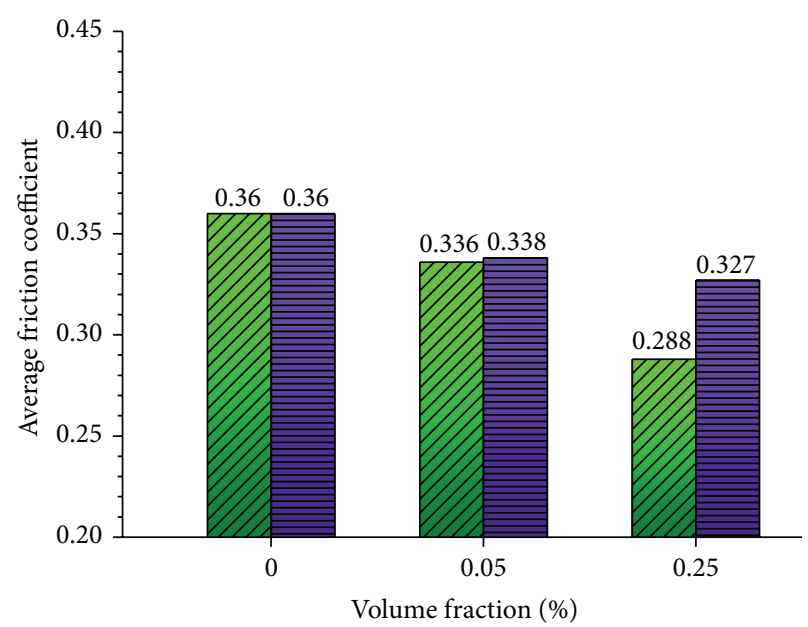

LB2000 + nanographite $(35 \mathrm{~nm})$ LB2000 + nanographite $(80 \mathrm{~nm})$

(b) $F=10 \mathrm{~N}$

FIGURE 4: Influence of volume fraction of graphite nanoparticles on average friction coefficient.

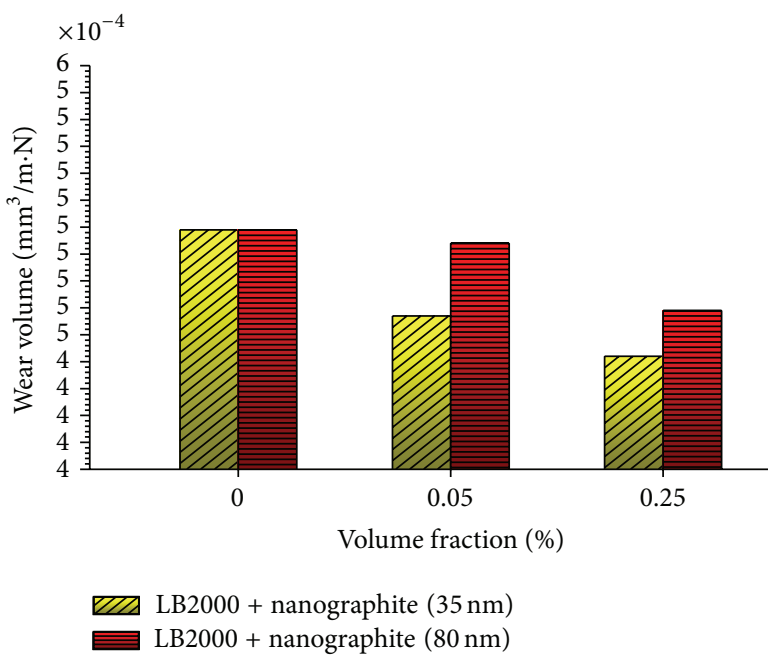

(a) $F=2 \mathrm{~N}$

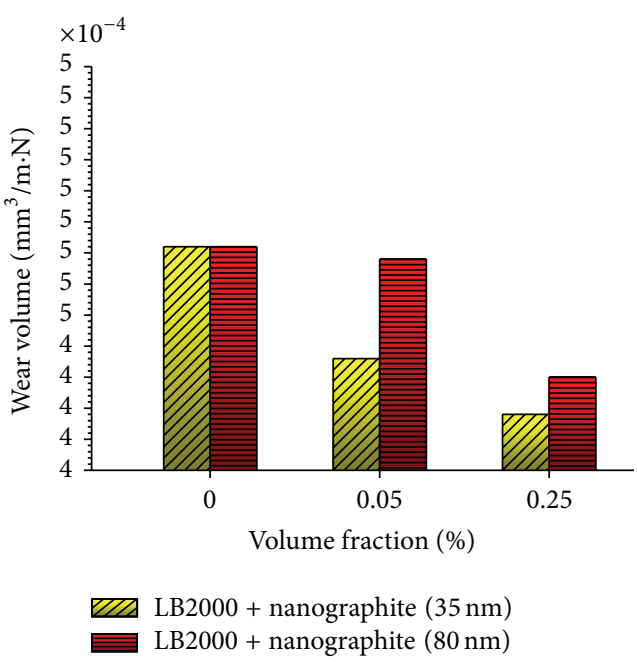

(b) $F=10 \mathrm{~N}$

FIGURE 5: Influence of volume fraction of graphite nanoparticles on wear volume of disk.

time, especially using vegetable based oil with graphite nanoparticles. This indicated that graphite nanoparticles played an important role in reducing the friction coefficient. By comparing Figure 3(a) with Figure 3(b), it can be found that, in case of vegetable based oil and vegetable based oil with graphite nanoparticles, the decrease in friction coefficient relative to dry friction became less when the normal force increased from $2 \mathrm{~N}$ to $10 \mathrm{~N}$.

Figure 4 shows the influence of volume fraction of graphite nanoparticles on friction-reducing property. In case of $0 \%$ volume fraction, it was a purely vegetable based oil lubrication process. As shown in Figure 4, increase in volume fraction of graphite nanoparticles resulted in the reduction in the average friction coefficient, regardless of particle size and normal force. This may be due to the fact that more graphite nanoparticles could enter into the contact surfaces. At the same volume fraction, graphiteLB2000 vegetable based oil nanofluids with $35 \mathrm{~nm}$ graphite nanoparticles presented a lower average friction coefficient than graphite-LB2000 vegetable based oil nanofluids with $80 \mathrm{~nm}$ graphite nanoparticles. This can be attributed to the fact that graphite nanoparticles with small size could more easily penetrate into the contact surfaces. At the normal force of 2 and $10 \mathrm{~N}$, the maximum reduction in average friction coefficient relative to pure LB2000 vegetable based oil was $53.23 \%$ and $20 \%$, respectively, which could be obtained using graphite-LB2000 nanofluids with $35 \mathrm{~nm}$ graphite nanoparticles with the volume fraction of $0.25 \%$. It can also be seen from Figure 4 that, in case of LB2000 vegetable based oil with or without graphite nanoparticles, increase in normal force led to the increase in average friction coefficient. 


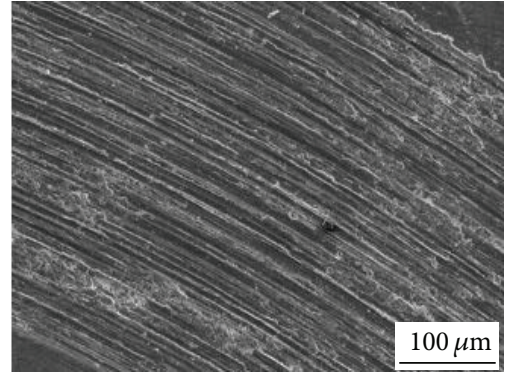

(a) $F=2 \mathrm{~N}$

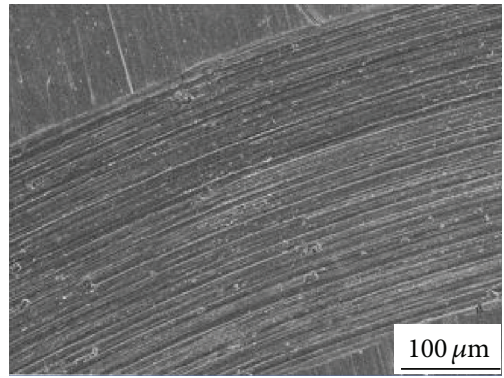

(c) $F=2 \mathrm{~N}$

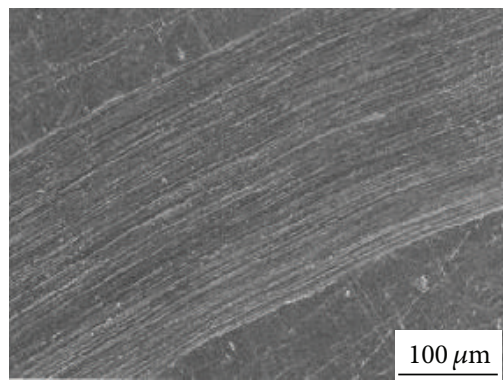

(e) $F=2 \mathrm{~N}$

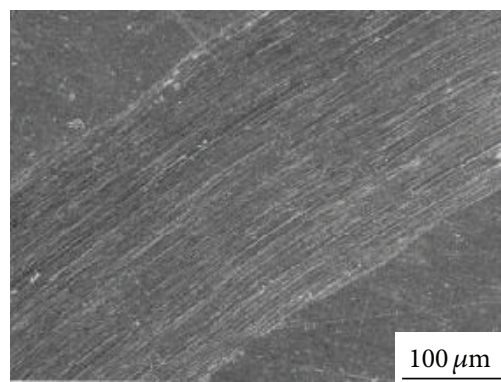

(g) $F=2 \mathrm{~N}$

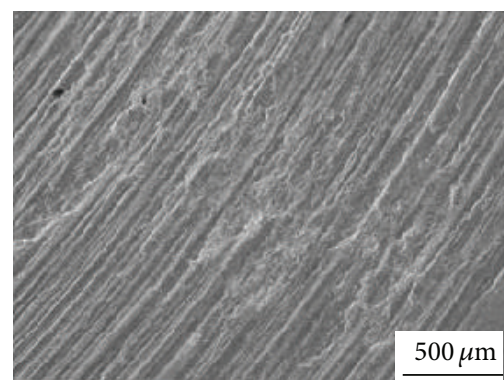

(b) $F=10 \mathrm{~N}$

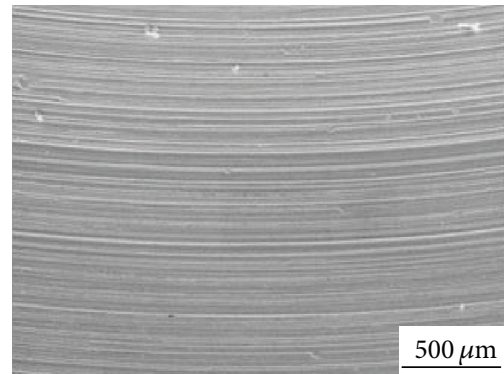

(d) $F=10 \mathrm{~N}$

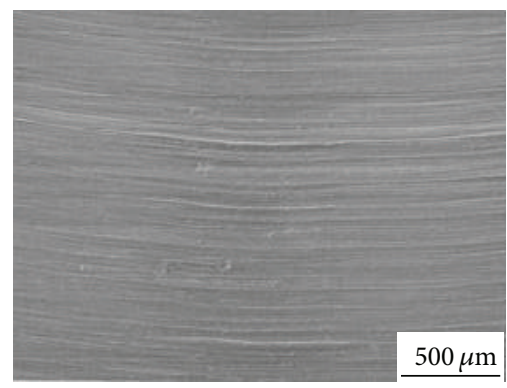

(f) $F=10 \mathrm{~N}$

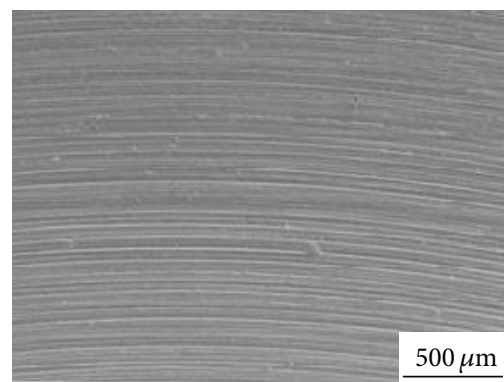

(h) $F=10 \mathrm{~N}$

FIGURE 6: FE-SEM morphologies of wear scars of disks for various lubrication conditions: ((a) and (b)) dry friction, ((c) and (d)) using LB2000 vegetable based oil without nanoparticles, ((e) and (f)) using vegetable based oil containing $35 \mathrm{~nm}$ graphite nanoparticles with the volume of $0.25 \%$, and $((\mathrm{g})$ and $(\mathrm{h}))$ using vegetable based oil containing $80 \mathrm{~nm}$ graphite nanoparticles with the volume of $0.25 \%$.

\subsection{Influence of Graphite Nanoparticles on Wear-Reduction} Capability of Vegetable Based Oil. Figure 5 shows the influence of volume fraction of graphite nanoparticles on the wear volume of disk. As shown in Figure 5, with the increase of volume fraction of graphite nanoparticles, the wear volume of disk decreased, irrespective of particle size and normal force. Moreover, when the volume fraction was the same, the smaller graphite nanoparticles, the lower wear volume. At the normal force of 2 and $10 \mathrm{~N}$, the maximum reduction in wear volume of disk with respect to pure LB2000 vegetable based oil was $9.61 \%$ and $11.44 \%$, respectively, which could be achieved using graphite-LB2000 nanofluids with $35 \mathrm{~nm}$ graphite nanoparticles with the volume fraction of $0.25 \%$. This suggested that the addition of graphite nanoparticles could enhance the wear-reduction capability of LB2000 vegetable based oil even at high normal force.

3.3. Surface Analysis. Figure 6 presents the FE-SEM morphologies of wear scars of disks for various lubrication conditions. It can be seen from Figure 6 that the wear scars 


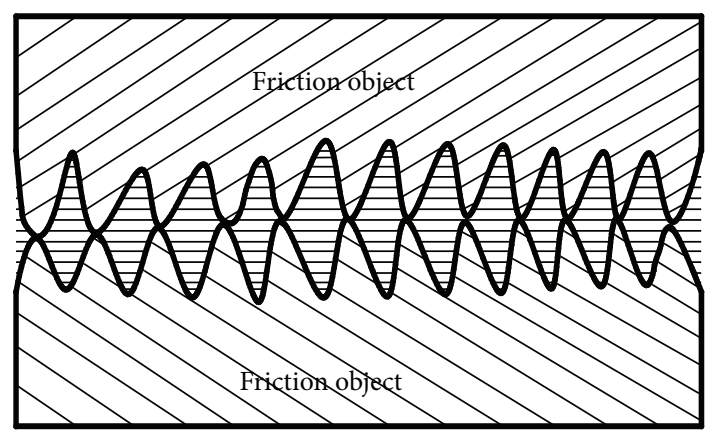

(a)

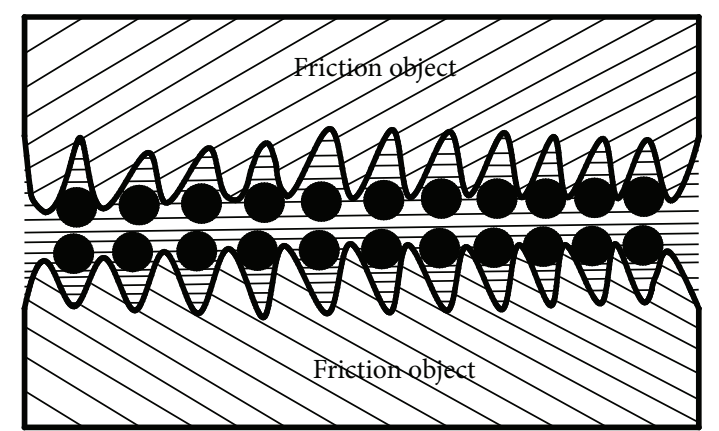

(b)

FIGURE 7: Schematic diagram of tribological model of nanoparticles during rubbing: (a) lubricated with pure oil, (b) lubricated with pure oil containing an appropriate of nanoparticles.

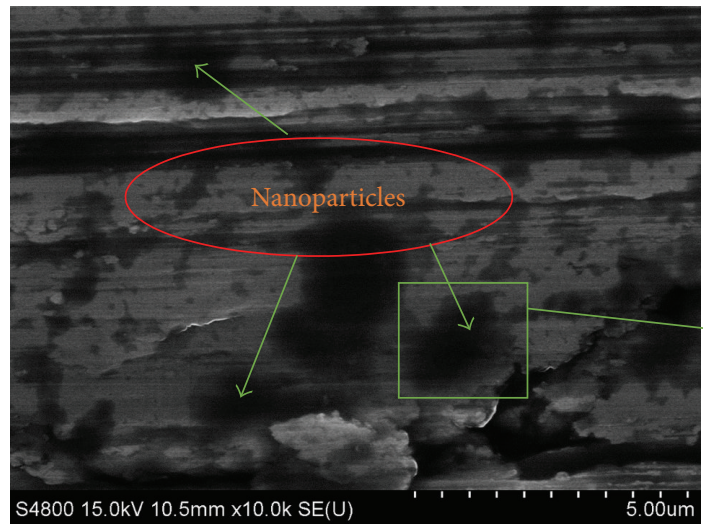

(a)

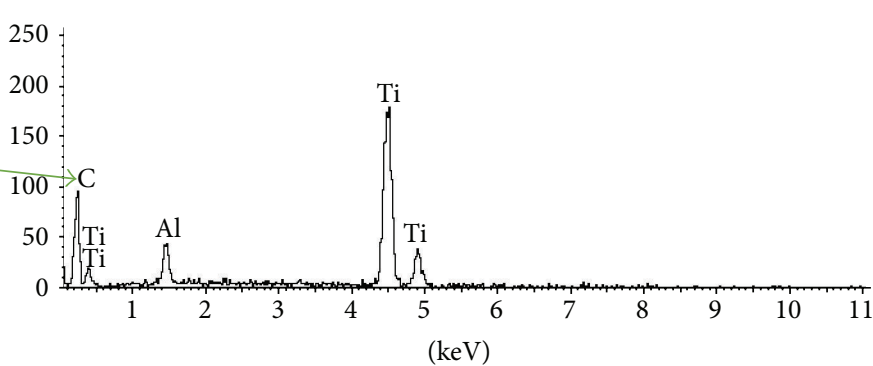

Full scale 256 cts cursor: 11.091 ( 0 cts)

(b)

FIGURE 8: FE-SEM and EDS analysis of surface of wear scar lubricated by the vegetable based oil-added 0.25 vol.\% graphite nanoparticles.

under dry friction condition were characterized by obvious scuffing and deep furrows (Figures 6(a) and 6(b)). Application of LB2000 vegetable based oil with or without graphite nanoparticles presented the smoother wear scars than dry friction condition, especially using LB2000 vegetable based oil containing graphite nanoparticles (Figures 6(c)-6(h)). Further, the furrows on the surfaces of wear scars were shallower and slender in case of LB2000 vegetable based oil containing graphite nanoparticles than those in case of pure LB2000 vegetable based oil, as shown in Figures 6(c)-6(h).

\subsection{Lubrication Mechanism of Graphite Nanoparticles as} Vegetable Based Oil Additive. Figure 7 shows the tribological model of nanoparticles as oil-based lubricant additive. As shown in Figure 7(a), contact surfaces can not be absolutely smooth. Further, the contact part is composed of a large number of convex and concave portions. Some convex portions contact with each other between friction surfaces. Although the load of contact surfaces is small, due to the fact that the surface area of convex portions is small, the convex portions are welded together because of partial high pressure, thus causing friction and wear. As shown in Figure 7(b), when a certain amount of nanoparticles is added into pure oil as additive, on one hand the nanoparticles can penetrate into the concave of friction surface and mend the damage position of friction surface effectively and on the other hand the nanoparticles might be deposited on the rubbing surface, which separates the contacting surfaces.

The lubrication mechanism of graphite nanoparticles as LB2000 vegetable based oil additive can be confirmed by the results of FE-SEM and EDS. As shown in Figure 8(a), as graphite nanoparticles owned small size and high surface energy, they could stably adsorb on the rubbing surfaces lubricated by LB2000 vegetable based oil, implying that graphite nanoparticles might form a physical deposition film on the rubbing surfaces. The EDS spectra of surface of wear scar lubricated by LB2000 vegetable based oil with graphite nanoparticles revealed a strong $C$ characteristic spectral line (Figure $8(\mathrm{~b})$ ). This indicated that graphite nanoparticles were transferred to the contact faces to lubricate the friction pairs.

\section{Conclusions}

Based on the investigation on the tribological properties of graphite nanoparticles as LB2000 vegetable based oil additive, the following conclusions can be drawn:

(1) Graphite nanoparticles could significantly improve the friction-reducing and antiwear properties of pure 
vegetable based oil. Increase in the volume fraction of graphite nanoparticles brought about the reduction in friction coefficient and wear volume of disk. Furthermore, at the same volume fraction, graphite nanoparticles with smaller particle size seemed more effective in reducing the friction coefficient and wear volume of disk.

(2) The addition of graphite nanoparticles in LB2000 vegetable based oil made the morphologies of wear scars smoother. Moreover, the furrows on the surfaces of wear scars were shallower and slender in case of LB2000 vegetable based oil with graphite nanoparticles than those in case of pure LB2000 vegetable based oil lubrication.

(3) Lubrication mechanism of graphite nanoparticles as vegetable based oil additive was that graphite nanoparticles could form a physical deposition film on the friction surfaces, owing to small size and high surface energy, consequently resulting in the decrease of friction coefficient and wear volume.

\section{Conflict of Interests}

The authors declare that there is no conflict of interests regarding the publication of this paper.

\section{Acknowledgments}

The authors wish to acknowledge the financial support of this research by National Natural Science Foundation of China under Contract no. 51205177, Natural Science Foundation of Jiangsu Province under Contract no. BK2012277, Natural Science Program for Basic Research of Jiangsu Province under Contract no. 08KJB460002, Qing Lan Project, and Research Fund of DML-HYIT (HGDML-0901).

\section{References}

[1] M. Amrita, R. R. Srikant, A. V. Sitaramaraju, M. Prasad, and P. V. Krishna, "Preparation and characterization of properties of nanographite-based cutting fluid for machining operations," Proceedings of the Institution of Mechanical Engineers, Part J: Journal of Engineering Tribology, vol. 228, no. 3, pp. 243-252, 2014.

[2] L. J. Pottuz, B. Vacher, N. Ohmae, J. M. Martin, and T. Epicier, "Anti-wear and friction reducing mechanisms of carbon nanoonions as lubricant additives," Tribology Letters, vol. 30, no. 1, pp. 69-80, 2008.

[3] M. Alberts, K. Kalaitzidou, and S. Melkote, "An investigation of graphite nanoplatelets as lubricant in grinding," International Journal of Machine Tools and Manufacture, vol. 49, no. 12-13, pp. 966-970, 2009.

[4] A. Marcon, S. Melkote, K. Kalaitzidou, and D. Debra, "An experimental evaluation of graphite nanoplatelet based lubricant in micro-milling," CIRP Annals-Manufacturing Technology, vol. 59, no. 1, pp. 141-144, 2010.

[5] K. H. Hu, M. Liu, Q. J. Wang, Y. F. Xu, S. Schraube, and X. G. Hu, "Tribological properties of molybdenum disulfide nanosheets by monolayer restacking process as additive in liquid paraffin," Tribology International, vol. 42, no. 1, pp. 33-39, 2009.

[6] D. Z. Jia, C. H. Li, D. K. Zhang, Y. B. Zhang, and X. Z. Zhang, "Experimental verification of nanoparticle jet minimum quantity lubrication effectiveness in grinding," Journal of Nanoparticle Research, vol. 16, no. 12, pp. 1-15, 2014.

[7] J. Kogovšek, M. Remškar, A. Mrzel, and M. Kalin, "Influence of surface roughness and running-in on the lubrication of steel surfaces with oil containing $\mathrm{MoS}_{2}$ nanotubes in all lubrication regimes," Tribology International, vol. 61, pp. 40-47, 2013.

[8] S. Bhaumik, S. Prabhu, and K. J. Singh, "Analysis of tribological behavior of carbon nanotube based industrial mineral gear oil 250 cSt viscosity," Advances in Tribology, vol. 2014, Article ID 341365, 8 pages, 2014.

[9] X. W. Pei, L. T. Hu, W. M. Liu, and J. C. Hao, "Synthesis of water-soluble carbon nanotubes via surface initiated redox polymerization and their tribological properties as water-based lubricant additive," European Polymer Journal, vol. 44, no. 8, pp. 2458-2464, 2008.

[10] C. Espejo, F.-J. Carrion, D. Martinez, and M.-D. Bermudez, "Multi-walled carbon nanotube-imidazolium tosylate ionic liquid lubricant," Tribology Letters, vol. 50, no. 2, pp. 127-136, 2013.

[11] H. D. Huang, J. P. Tu, L. P. Gan, and C. Z. Li, "An investigation on tribological properties of graphite nanosheets as oil additive," Wear, vol. 261, no. 2, pp. 140-144, 2006.

[12] C.-G. Lee, Y.-J. Hwang, Y.-M. Choi, J.-K. Lee, C. Choi, and J.M. Oh, "A study on the tribological characteristics of graphite nano lubricants," International Journal of Precision Engineering and Manufacturing, vol. 10, no. 1, pp. 85-90, 2009.

[13] B. K. Prasad, S. Rathod, M. S. Yadav, and O. P. Modi, "Sliding wear behavior of cast iron: influence of $\mathrm{MoS}_{2}$ and graphite addition to the oil lubricant," Journal of Materials Engineering and Performance, vol. 20, no. 3, pp. 445-455, 2011.

[14] Y. J. Hwang, C. G. Lee, Y. M. Choi et al., "Effect of the size and morphology of particles dispersed in nano-oil on friction performance between rotating discs," Journal of Mechanical Science and Technology, vol. 25, no. 11, pp. 2853-2857, 2011.

[15] V. An, Y. Irtegov, and C. de Izarra, "Study of tribological properties of nanolamellar WS $\mathrm{Wn}_{2}$ and $\mathrm{MoS}_{2}$ as additives to lubricants," Journal of Nanomaterials, vol. 2014, Article ID 865839, 8 pages, 2014.

[16] D. L. Cursaru, C. Andronescu, C. Pirvu, and R. Ripeanu, "The efficiency of Co-based single-wall carbon nanotubes (SWNTs) as an AW/EP additive for mineral base oils," Wear, vol. 290-291, pp. 133-139, 2012. 

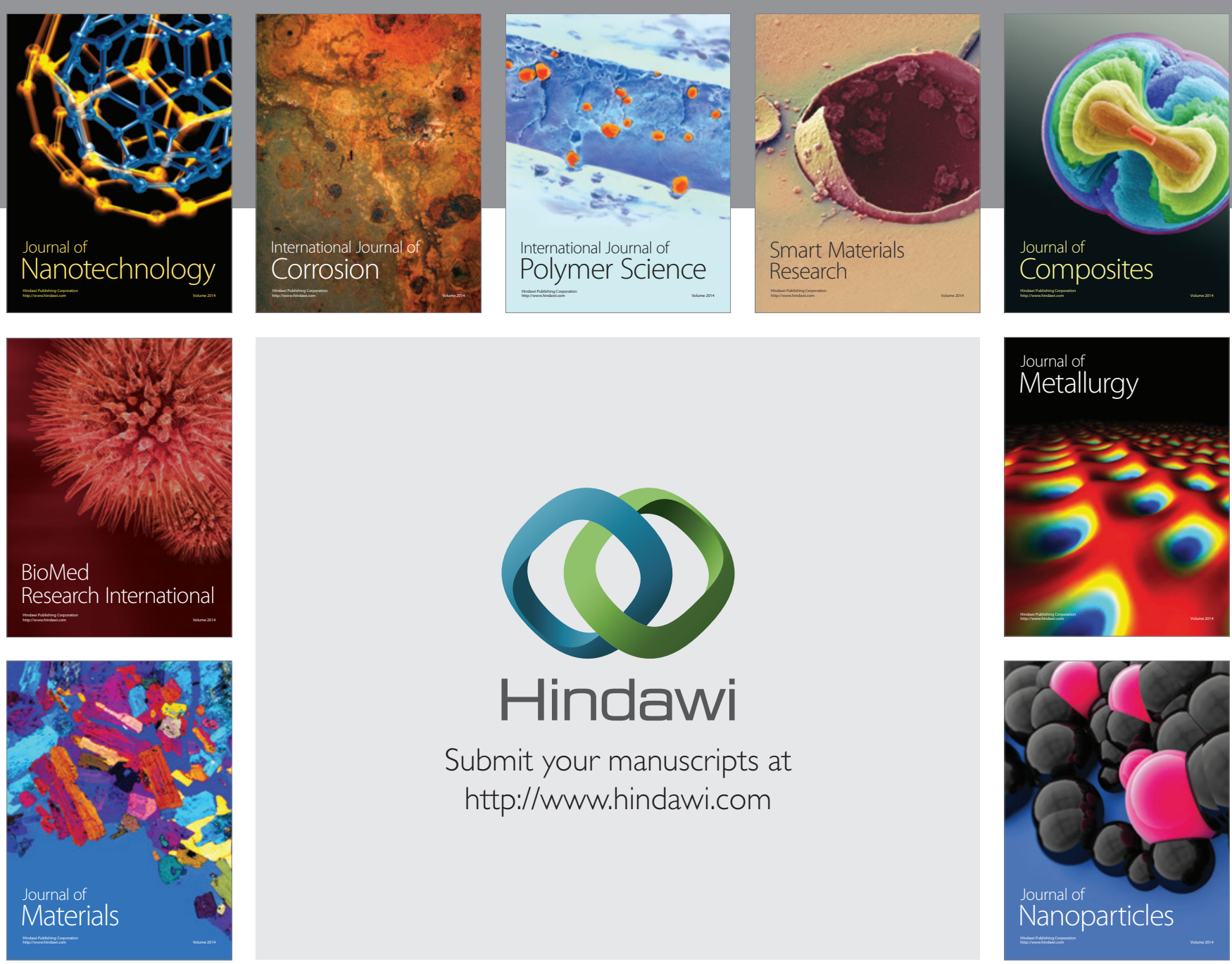

Submit your manuscripts at http://www.hindawi.com
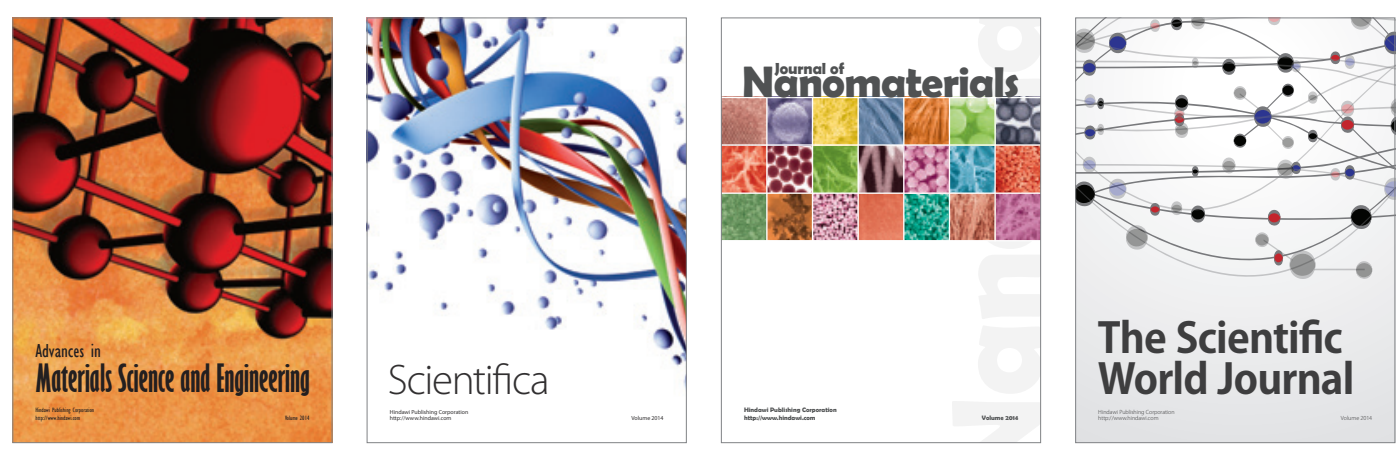

\section{The Scientific World Journal}
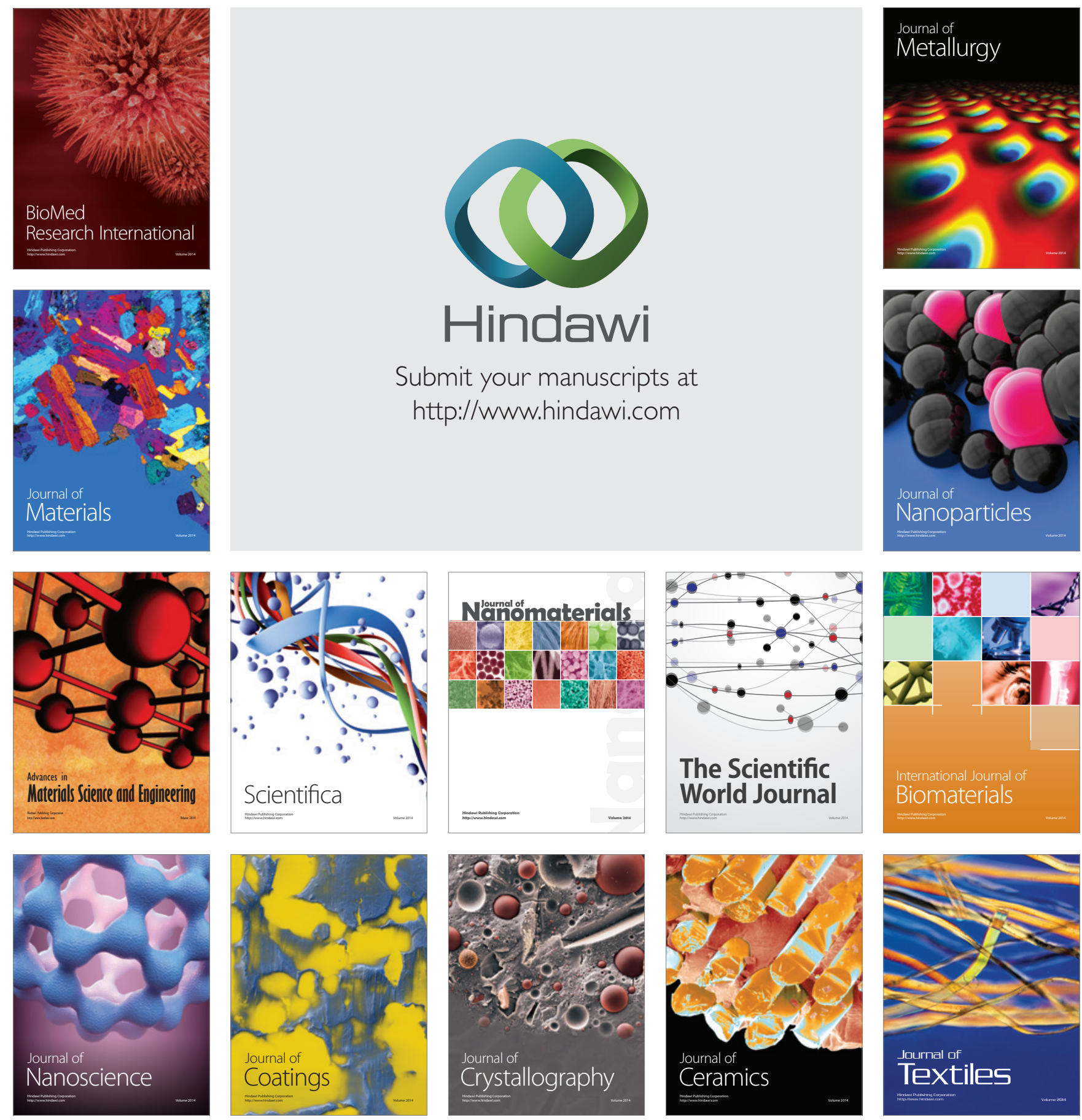